\title{
Perceptions of Patient-Provider Communication Across the Six Largest Asian Subgroups in the USA
}

\author{
James B. Kirby, $P h D^{7}$ (D), Terceira A. Berdahl, $P h D^{7}$, and Rosalie A. Torres Stone, $P h D^{2}$ \\ ${ }^{1}$ Agency for Healthcare Research and Quality, Center for Financing, Access and Cost Trends, Rockville, MD, USA; ${ }^{2}$ Department of Sociology, Clark \\ University, Worcester, MA, USA.
}

\begin{abstract}
BACKGROUND: Asians are the fastest-growing racial/ ethnic minority group in the USA and many face communication barriers when seeking health care. Given that a high proportion of Asians are immigrants and have limited English proficiency, poor patient-provider communication may explain Asians' relatively low ratings of care. Though Asians are linguistically, economically, and culturally heterogeneous, research on health care disparities typically combines Asians into a single racial/ethnic category.
\end{abstract}

OBJECTIVES: To estimate racial/ethnic differences in perceptions of provider communication among the six largest Asian subgroups.

DESIGN AND PARTICIPANTS: Using a nationally representative sample of adults from the 2014-2017 Medical Expenditure Panel Survey $(N=136,836$, round-specific response rates range from $72 \%$ to $98 \%$ ), we estimate racial/ethnic differences in perceptions of provider communication, adjusted for English proficiency, immigration status, and sociodemographic characteristics.

MAIN MEASURES: The main dependent variable is a 4item scale ranging from 0 to 100 measuring how positively patients view their health care providers' communication, adapted from the Consumer Assessment of Healthcare Providers and Systems (CAHPS $\odot$ ) program. Respondents report how often their providers explain things clearly, show respect, listen carefully, and spend enough time with them.

KEY RESULTS: Asians, overall, had less positive perceptions of their providers' communication than either Whites or Latinxs. However, only Chinese-White differences remained after differences in English proficiency and immigration status were controlled (difference $=-2.67$, 95\% CI - 4.83, - 0.51). No other Asian subgroup differed significantly from Whites.

CONCLUSIONS: Negative views of provider communication are not pervasive among all Asians but, rather, primarily reflect the perceptions of Chinese and, possibly, Vietnamese patients. Researchers, policymakers, health plan executives, and others who produce or use data on patients' experiences with health care should, if possible, avoid categorizing all Asians into a single group.

KEY WORDS: patient-provider communication; racial/ethnic disparities; health care quality.

Received February 25, 2020

Accepted December 3, 2020

Published online February 9, 2021
J Gen Intern Med 36(4):888-93

DOI: $10.1007 / \mathrm{s} 11606-020-06391-\mathrm{Z}$

(C) This is a U.S. government work and not under copyright protection in the U.S.; foreign copyright protection may apply 2021

\section{INTRODUCTION}

Racial/ethnic minorities tend to report less positive health care experiences than non-Latinx-Whites (Whites) ${ }^{1-3}$ and, among minority groups, non-Latinx Asians (Asians) report the least positive experiences. ${ }^{1,4,5}$ Given that a relatively high proportion of Asians in the USA are immigrants and have limited English proficiency, their relatively negative perceptions of care could be due in part to poor patient-provider communication, a critical component of high-quality health care. ${ }^{6}$ Research on racial/ethnic disparities in the US health care system typically homogenizes the Asian experience by combining Asians into a single racial/ethnic category. This hampers improvements in understanding Asian-White differences in how positively experiences with care are perceived. It is increasingly important for research to address this limitation because Asians are now the fastest-growing racial/ethnic minority group in the USA, with Asian immigrants outnumbering Latinx immigrants by 6.1 million in 2016 alone (37.1 million vs. 31.0 million). ${ }^{7}$ In this study, we use nationally representative data from the 2014-2017 Medical Expenditure Panel Survey (MEPS) to estimate racial/ethnic differences in how positively respondents view their health care providers' communication with a special focus on the six largest Asian subgroups in the USA.

\section{Background}

Asians in the USA view their health care less positively than other racial/ethnic groups and provider communication is among the aspects of care that Asians view less positively. ${ }^{8-15}$ For example, in a nationally representative survey of 6722 adults, compared to Latinx, African American, and White patients, Asians were more likely to report that their physicians looked down on them and the way they live their lives. ${ }^{10}$ Another study using the same data revealed that, compared to Whites, Asians were more likely to report that their regular doctor did not understand their background and values, and did not listen, spend enough time, or involve them in treatment decisions as much as they wanted. ${ }^{12}$ Health plan survey data 
generally support these findings. In a representative sample of 2013 Medicare beneficiaries, for example, Asians less often reported that their providers discussed their medications and had up-to-date information on care from specialists compared to White beneficiaries. ${ }^{16}$

Asian-White differences in perceptions of care have been found using different types of data (e.g., national survey data, ${ }^{10,12}$ health plan data, ${ }^{8,16-19}$ and qualitative interviews ${ }^{13}$ ), in different subpopulations (e.g., cancer survivors ${ }^{14}$ ), and in different types of health plans (e.g., Medicaid managed care, ${ }^{18,19}$ Medicare Part $\mathrm{D}^{8}$ ). It is unclear, however, whether the Asian-White differences in the USA documented by previous studies reflect views of care that are pervasive across all Asian subgroups. In the UK, ethnic differences in patient experiences have been documented in much more detail, including differences across Asian subgroups. ${ }^{20-22}$ This is largely due to the availability of data from the General Practice Patient Survey, which collects information about patient experiences and perceptions from over 2.2 million people annually. ${ }^{23}$ There is no comparable data source in the USA and, consequently, most studies on ethnic differences in patient experiences must use a single category to describe all Asians. Those that do examine Asian subgroups typically rely on samples that are not nationally representative (e.g., health plan data or small, convenience samples) ${ }^{11,13}$.

In this study, we use nationally representative data to estimate racial/ethnic differences in how positively adult patients view their health care providers' communication, making separate estimates for the six largest Asian subgroups in the USA. To explore the factors that might explain the differences we observe, we present both unadjusted differences and differences adjusted for English proficiency, immigration status, and a variety of socioeconomic and demographic characteristics.

\section{METHODS}

\section{Data}

We analyzed data on a sample of non-Latinx-White (White), non-Latinx Asian (Asian,) and Latinx adults from the 2014 2017 Medical Expenditure Panel Survey (MEPS), an ongoing annual household survey of the US non-institutionalized population sponsored by the Agency for Healthcare Research and Quality (AHRQ). The overlapping panel design of MEPS enables us to pool 4 years of data, which yields a sample sufficient to make separate estimates on several measures of provider communication for Chinese, Asian Indians, Filipinos, Japanese, Korean, and Vietnamese $(N=136,836$, annual response rates range from 44 to $49 \%$ ).

\section{Variables}

The main dependent variable is a scale made up of four items measuring respondents' perceptions of communication with their health care providers during the previous 12 months.
Individuals were first asked, "In the last 12 months, not counting the times you went to an emergency room, how many times did you go to a doctor's office or clinic to get health care for yourself?" Those who reported having at least one visit were asked how often "doctors or other health providers" explained things in a way that was easy to understand, listened carefully, showed respect for what they had to say, and spent enough time with them. Possible responses were "never," "sometimes," "usually," or "always." These questions were adapted from version 4.0 of the CAHPS Health Plan questionnaire developed by AHRQ.

We used linear mean scoring to create a scale for respondents' perceptions of provider communication ranging from 0 (most negative) to 100 (most positive), a method used by prior studies. ${ }^{24-26}$ The reliability coefficient (Cronbach's Alpha) of the resulting provider communication scale is 0.88 .

There are several individual characteristics that differ across the racial/ethnic groups that could explain some or all of the differences observed in perceived provider communication. English proficiency and immigration status are perhaps the most obvious; limited English proficiency (LEP) is more common among Asians and Latinxs than among Whites, and Asians and Latinxs are both more likely to be recent immigrants. We measure English proficiency with dummy variables identifying people who report speaking English "very well", "well", "not well", "not at all" and immigration status with dummy variables identifying people who were born in the USA, immigrated more than 15 years ago, immigrated between 10 and 15 years ago, immigrated between 5 and 10 years ago, or immigrated less than 5 years ago.

Socioeconomic status differs across racial and ethnic categories and it too is likely associated with patient-provider communication. We use dummy variables to measure household income as a percent of the federal poverty line $(<100 \%, 100$ $124 \%, 125-199 \% \%, 200-300 \%$, or $>400 \%$ ), educational attainment (no high school diploma/GED, high school diploma/ GED only, 4-year college degree or graduate/professional degree), and insurance coverage stratified by age ( $<65$ private, $<$ 65 public, $<65$ uninsured, $65+$ Medicare only, $65+$ Medicare and private, and 65+ Medicare and Medicaid).

Health status differs by race/ethnicity and, at the same time, may affect communication with health care providers. For example, discussing the management of chronic conditions with a provider may require more nuanced language than discussing general health issues. We use dummy variables to capture self-rated health (poor, fair, good, very good, or excellent) and the presence of chronic conditions $(0,1$, or multiple chronic conditions). Finally, our analysis includes variables measuring age, sex, rural-urban residence, and region of the country.

\section{Analytic Approach}

We first estimate the unadjusted means of the provider communication scale for each racial/ethnic group. We then 
estimate adjusted racial/ethnic differences in the provider communication scale relative to Whites using three linear regression models. The first model includes only the dummy variables identifying racial/ethnic groups, the second model includes the English proficiency and immigration variables, and the final model includes all variables described previously. We present only a subset of the coefficient estimates; a complete set of coefficient estimates is available upon request. All analyses use survey weights equal to the inverse probability of being selected into the sample, which make estimates nationally representative. Confidence intervals are corrected for clustering at the survey strata-level and below using the Taylor-series linearization approach implemented in the survey estimation procedures available in Stata Version 16.0. ${ }^{27}$

\section{RESULTS}

Consistent with previous research, Asians' perceptions of their providers' communication are less positive than either that of Whites or Latinxs. On a 0 to 100 scale, Asians score 83.4, compared to 85.7 for Whites (Table 1). This difference, however, is due largely to the scores of Chinese (81.7) and Vietnamese (81.0) respondents. These differences may appear modest, but the distribution of the provider communication scale is highly concentrated at the high end of the range, with more than half of the sample scoring above 90 . The difference in the mean provider communication scale between Chinese and Whites, for example, is about $30 \%$ of the scale's standard deviation in the overall sample. The Wald $F$-test enables us to reject the null hypothesis that the mean of the provider communication scale is the same for all Asians, indicating that perceptions of provider communication vary significantly across the Asian subgroups. Pairwise contrasts (not shown) indicate that the mean for the Chinese subgroup is statistically different from both that of the Filipino subgroup and the Asian Indian subgroup, as is the mean for the Vietnamese subgroup.

The unadjusted differences in perceptions of provider communication could be due to differences in English proficiency, immigration status, or various demographic, socioeconomic, and health characteristics. Compared to Whites, for example, Chinese respondents were more likely to be foreign-born (73.3\% vs $4 \%$, Table 2 ) and more likely to report speaking English "not well" or "not at all" (19.6\% vs $0.4 \%$, Table 2). Asians, overall, did not differ from Whites in the percent in poverty and had a significantly higher percentage of individuals with college degrees. Results from the multivariable analysis will shed light on the extent to which the racial/ ethnic differences in Table 2 account for the differences in provider communication shown in Table 1 .

Comparing results from model 1 with those from model 2 (Table 3) suggests that differences in English proficiency and immigration status alone account for about $56 \%$ of the LatinxWhite difference in provider communication $(-2.00$ to -0.89$)$ but only about $31 \%$ of the Chinese-White difference ( -3.85 to $-2.65)$ and $33 \%$ of the Vietnamese-White difference $(-4.34$ to -2.92 ). Results from model 3 show that the Chinese-White difference in perceived provider communication is not further reduced when household income, education, insurance status, health status, and the demographic variables are included in

Table 1 Descriptive Statistics for the Provider Communication Scale and the Four Component Indicators by Race and Ethnicity

\begin{tabular}{|c|c|c|c|c|c|c|}
\hline & \multirow[t]{2}{*}{$\mathbf{N}$} & \multirow[t]{2}{*}{$\begin{array}{l}\text { Provider communication } \\
\text { scale composite (mean) }\end{array}$} & \multicolumn{4}{|c|}{$\begin{array}{l}\text { Component indicators of the provider communication scale: percent who report } \\
\text { that providers "always" }\end{array}$} \\
\hline & & & Explained clearly & $\begin{array}{l}\text { Listened } \\
\text { carefully }\end{array}$ & Showed respect & $\begin{array}{l}\text { Spent enough } \\
\text { time }\end{array}$ \\
\hline Overall, 95\% CI & 136,836 & $85.3(85.1,85.6)$ & \multirow{11}{*}{$\begin{array}{l}65.4 \% \\
(64.7 \%, 66.1 \%) \\
65.8 \% \\
(64.9 \%, 66.6 \%) \\
63.6 \% * \\
(62.1 \%, 65.1 \%) \\
53.2 \% * * * \\
(47.3 \%, 59.1 \%) \\
65.2 \% \\
(59.8 \%, 70.6 \%) \\
65.2 \% \\
(59.8 \%, 70.5 \%) \\
59.4 \% * \\
(53.5 \%, 65.3 \%) \\
60.3 \% \\
(52.7 \%, 67.9 \%) \\
54.1 \% * * \\
(46.8 \%, 61.5 \%) \\
59.2 \% * * * \\
(56.5 \%, 62.0 \%) \\
F(5,342)=3.44, \\
\text { Prob }>F=0.005\end{array}$} & \multirow{11}{*}{$\begin{array}{l}64.6 \% \\
(63.8 \%, 65.4 \%) \\
64.6 \% \\
(63.6 \%, 65.5 \%) \\
62.6 \% * \\
(61.1 \%, 64.1 \%) \\
55.2 \% * * \\
(49.9 \%, 60.4 \%) \\
65.0 \% \\
(59.5 \%, 70.6 \%) \\
66.8 \% \\
(62.1 \%, 71.6 \%) \\
63.7 \% \\
(56.7 \%, 70.7 \%) \\
58.7 \% \\
(51.2 \%, 66.3 \%) \\
59.1 \% \\
(52.0 \%, 66.1 \%) \\
61.3 \% * * * \\
(58.8 \%, 63.8 \%) \\
F(5,342)=2.94, \\
\text { Prob >F=0.013 }\end{array}$} & \multirow{11}{*}{$\begin{array}{l}69.3 \% \\
(68.6 \%, 70.0 \%) \\
69.0 \% \\
(68.1 \%, 69.9 \%) \\
69.3 \% \\
(67.9 \%, 70.7 \%) \\
60.0 \% * * \\
(54.3 \%, 65.7 \%) \\
67.6 \% \\
(62.4 \%, 72.7 \%) \\
74.0 \% * \\
(69.4 \%, 78.7 \%) \\
68.9 \% \\
(63.1 \%, 74.7 \%) \\
66.8 \% \\
(59.1 \%, 74.4 \%) \\
63.4 \% \\
(56.6 \%, 70.1 \%) \\
66.3 \% * * * \\
(63.9 \%, 68.7 \%) \\
F(5,342)=3.99, \\
\text { Prob }>F=0.002\end{array}$} & \multirow{11}{*}{$\begin{array}{l}56.8 \% \\
(56.1 \%, 57.5 \%) \\
57.4 \% \\
(56.5 \%, 58.3 \%) \\
53.3 \% * * * \\
(51.7 \%, 54.8 \%) \\
41.8 \% * * * \\
(36.3 \%, 47.3 \%) \\
53.4 \% \\
(48.7 \%, 58.2 \%) \\
59.8 \% \\
(55.1 \%, 64.5 \%) \\
56.2 \% \\
(48.3 \%, 64.1 \%) \\
46.6 \% * * * \\
(38.6 \%, 54.6 \%) \\
49.8 \% \\
(42.1 \%, 57.6 \%) \\
51.0 \% * * * \\
(48.2 \%, 53.8 \%) \\
F(5,342)=6.70, \\
\text { Prob }>F=0.000\end{array}$} \\
\hline $\begin{array}{l}\text { Non-Latinx- } \\
\text { Whites, } 95 \% \text { CI }\end{array}$ & 53,259 & $85.7(85.4,86.1)$ & & & & \\
\hline Latinx, $95 \%$ CI & 42,595 & $83.9 * * *(83.3,84.5)$ & & & & \\
\hline Chinese, 95\% CI & 2571 & $81.7 * * *(79.6,83.7)$ & & & & \\
\hline Indian, $95 \% \mathrm{CI}$ & 2371 & $84.7(82.5,86.9)$ & & & & \\
\hline Filipino, 95\% CI & 2036 & $85.8(83.9,87.7)$ & & & & \\
\hline Japanese, $95 \%$ CI & 757 & $84.2(81.1,87.4)$ & & & & \\
\hline Korean, 95\% CI & 800 & $83.0(80.3,85.8)$ & & & & \\
\hline $\begin{array}{l}\text { Vietnamese, } 95 \% \\
\text { CI }\end{array}$ & 945 & $81.0 * *(78.1,83.9)$ & & & & \\
\hline $\begin{array}{l}\text { Asian (overall), } \\
95 \% \text { CI }\end{array}$ & 10,887 & $83.4 * * *(82.4,84.4)$ & & & & \\
\hline $\begin{array}{l}\text { Wald } F \text {-test of joint } \\
\text { of means across As } \\
\text { subgroups }\end{array}$ & equality & $\begin{array}{l}F(5,342)=3.01 \\
\text { Prob }>F=0.011\end{array}$ & & & & \\
\hline
\end{tabular}

Overall scale reliability (coefficient alpha): 0.88

$* p 0.05$, ** $p<0.01$, and $* * * p<0.001$ indicate statistically significant difference from Whites 
Table 2 Descriptive Statistics for Select Linguistic, Demographic and Socioeconomic Characteristics by Race and Ethnicity

\begin{tabular}{|c|c|c|c|c|c|c|}
\hline & LEP & Foreign-Born & $\begin{array}{l}\text { Poverty } \\
(<100 \% \text { FPL })\end{array}$ & $\begin{array}{l}\text { 4-year college } \\
\text { degree }\end{array}$ & Uninsured & $\begin{array}{l}\text { Fair or poor } \\
\text { health }\end{array}$ \\
\hline Overall, 95\% CI & $\begin{array}{l}4.1 \% \\
(3.6 \%, 4.5 \%)\end{array}$ & $\begin{array}{l}14.1 \% \\
(13.3 \%, 15.0 \%)\end{array}$ & $\begin{array}{l}10.0 \% \\
(9.4 \%, 10.6 \%)\end{array}$ & $\begin{array}{l}35.1 \% \\
(33.8 \%, 36.3 \%)\end{array}$ & $\begin{array}{l}4.3 \% \\
(3.9 \%, 4.6 \%)\end{array}$ & $\begin{array}{l}15.7 \% \\
(15.1 \%, 16.3 \%)\end{array}$ \\
\hline $\begin{array}{l}\text { Non-Latinx-Whites, } 95 \% \\
\text { CI } \\
\text { Latinx, } 95 \% \text { CI }\end{array}$ & $\begin{array}{l}0.4 \% \\
(0.2 \%, 0.5 \%) \\
24.8 \% * * *\end{array}$ & $\begin{array}{l}4.0 \% \\
(3.6 \%, 4.5 \%) \\
50.2 \% * * *\end{array}$ & $\begin{array}{l}7.6 \% \\
(7.0 \%, 8.1 \%) \\
15.5 \% * * *\end{array}$ & $\begin{array}{l}38.4 \% \\
(36.9 \%, 39.9 \%) \\
19.0 \% * * *\end{array}$ & $\begin{array}{l}2.9 \% \\
(2.5 \%, 3.2 \%) \\
11.8 \% * * *\end{array}$ & $\begin{array}{l}14.1 \% \\
(13.4 \%, 14.8 \%) \\
21.5 \% \text { *** }\end{array}$ \\
\hline Latinx, 95\% CI & $\begin{array}{l}24.8 \% * * * \\
(22.9 \%, 26.7 \%)\end{array}$ & $\begin{array}{l}50.2 \% * * \\
(47.8 \%, 52.7 \%)\end{array}$ & $\begin{array}{l}15.5 \% * * * \\
(14.0 \%, 16.9 \%)\end{array}$ & $\begin{array}{l}19.0 \% * * * \\
(17.2 \%, 20.7 \%)\end{array}$ & $(10.6 \%, 13.0 \%)$ & $(20.0 \%, 22.9 \%)$ \\
\hline Chinese, 95\% CI & $\begin{array}{l}19.6 \% * * * \\
(14.5 \%, 24.6 \%)\end{array}$ & $\begin{array}{l}73.3 \% * * * \\
(66.6 \%, 80.0 \%)\end{array}$ & $\begin{array}{l}9.1 \% \\
(5.8 \%, 12.4 \%)\end{array}$ & $\begin{array}{l}60.5 \% * * * \\
(55.3 \%, 65.7 \%)\end{array}$ & $\begin{array}{l}2.0 \% \\
(0.6 \%, 3.3 \%)\end{array}$ & $\begin{array}{l}12.5 \% \\
(9.2 \%, 15.9 \%)\end{array}$ \\
\hline Indian, $95 \% \mathrm{CI}$ & $\begin{array}{l}5.4 \% * * \\
(2.1 \%, 8.8 \%)\end{array}$ & $\begin{array}{l}80.6 \% * * * \\
(75.1 \%, 86.2 \%)\end{array}$ & $\begin{array}{l}5.9 \% \\
(3.2 \%, 8.6 \%)\end{array}$ & $\begin{array}{l}68.2 \% * * * \\
(61.2 \%, 75.1 \%)\end{array}$ & $\begin{array}{l}2.5 \% \\
(1.3 \%, 3.7 \%)\end{array}$ & $\begin{array}{l}6.5 \% * * * \\
(4.3 \%, 8.6 \%)\end{array}$ \\
\hline Filipino, $95 \% \mathrm{CI}$ & $\begin{array}{l}3.3 \% * * \\
(1.4 \%, 5.2 \%)\end{array}$ & $\begin{array}{l}70.4 \% * * * \\
(63.9 \%, 76.9 \%)\end{array}$ & $\begin{array}{l}4.6 \% * * \\
(2.5 \%, 6.7 \%)\end{array}$ & $\begin{array}{l}46.8 \% * * \\
(39.2 \%, 54.4 \%)\end{array}$ & $\begin{array}{l}3.2 \% \\
(1.3 \%, 5.2 \%)\end{array}$ & $\begin{array}{l}11.4 \% \\
(7.8 \%, 15.0 \%)\end{array}$ \\
\hline Japanese, 95\% CI & $\begin{array}{l}2.9 \% * \\
(0.5 \%, 5.2 \%)\end{array}$ & $\begin{array}{l}36.8 \% * * * \\
(21.7 \%, 51.9 \%)\end{array}$ & $\begin{array}{l}5.4 \% \\
(2.9 \%, 7.8 \%)\end{array}$ & $\begin{array}{l}49.7 \% * * \\
(40.7 \%, 58.6 \%)\end{array}$ & $\begin{array}{l}1.6 \% * \\
(0.3 \%, 2.8 \%)\end{array}$ & $\begin{array}{l}9.6 \% \text { ** } \\
(6.1 \%, 13.1 \%)\end{array}$ \\
\hline Korean, $95 \%$ CI & $\begin{array}{l}29.7 \% * * * \\
(19.0 \%, 40.3 \%)\end{array}$ & $\begin{array}{l}76.1 \% * * * \\
(68.9 \%, 83.4 \%)\end{array}$ & $\begin{array}{l}11.2 \% \\
(4.5 \%, 17.9 \%)\end{array}$ & $\begin{array}{l}50.7 \% * * \\
(39.8 \%, 61.6 \%)\end{array}$ & $\begin{array}{l}1.6 \% \\
(-0.3 \%, 3.5 \%)\end{array}$ & $\begin{array}{l}19.8 \% \\
(11.1 \%, 28.6 \%)\end{array}$ \\
\hline Vietnamese, $95 \%$ CI & $\begin{array}{l}38.9 \% * * * \\
(29.9 \%, 47.9 \%)\end{array}$ & $\begin{array}{l}77.9 \% * * * \\
(70.0 \%, 85.9 \%)\end{array}$ & $\begin{array}{l}15.5 \% * * \\
(9.6 \%, 21.3 \%)\end{array}$ & $\begin{array}{l}29.9 \% \\
(20.6 \%, 39.2 \%)\end{array}$ & $\begin{array}{l}2.3 \% \\
(0.3 \%, 4.2 \%)\end{array}$ & $\begin{array}{l}19.5 \% * \\
(14.6 \%, 24.3 \%)\end{array}$ \\
\hline Asian (overall), $95 \%$ CI & $\begin{array}{l}14.0 \% * * * \\
(11.6 \%, 16.3 \%)\end{array}$ & $\begin{array}{l}72.5 \% * * * \\
(67.6 \%, 77.5 \%)\end{array}$ & $\begin{array}{l}8.2 \% \\
(6.6 \%, 9.8 \%)\end{array}$ & $\begin{array}{l}54.7 \% * * * \\
(51.0 \%, 58.4 \%)\end{array}$ & $\begin{array}{l}2.4 \% \\
(1.7 \%, 3.1 \%)\end{array}$ & $\begin{array}{l}11.7 \% * * * \\
(10.1 \%, 13.3 \%)\end{array}$ \\
\hline Wald $F$-test: & $F(5,342)=$ & $F(5,342)=8.01$ & $F(5,342)=5.05$ & $F(5,342)=$ & $F(5,342)=0.72$ & $F(5,342)=5.95$ \\
\hline $\begin{array}{l}\mathrm{H}_{0} \text { : Means do not differ } \\
\text { across Asian subgroups }\end{array}$ & $\begin{array}{l}21.55 \\
\text { Prob. }>F=0.00\end{array}$ & Prob. $>F=0.00$ & Prob. $>F=0.00$ & $\begin{array}{l}10.47 \\
\text { Prob. }>F=0.00\end{array}$ & Prob. $>F=0.61$ & Prob. $>F=0.00$ \\
\hline
\end{tabular}

$* p 0.05, * * p<0.01$, and $* * * p<0.001$ indicate statistically significant difference from whites

the model. Furthermore, the Chinese-White difference is the only racial/ethnic difference to remain statistically significant $(-2.67)$. The Vietnamese-White difference, while statistically insignificant at $p<0.05$, is still fairly large $(-2.20)$ and the imprecision of the estimate is due to the relatively small sample of Vietnamese. In contrast, the Latinx-White difference in perceived provider communication not only becomes statistically insignificant in model 3 but also changes signs (0.71).

The Wald $F$-test indicates that even after adjusting for English proficiency, immigration status, and all the other socioeconomic and demographic variables, the mean of the provider communication scale still varies across the Asian subgroups. Test of the pairwise differences across the Asian subgroups shows that the mean of the provider communication scale for

Table 3 Coefficient Estimates for Select Variables from OLS Regression Models on the Provider Communication Scale

\begin{tabular}{|c|c|c|c|c|c|c|}
\hline \multirow[t]{2}{*}{ Independent variables } & \multicolumn{2}{|l|}{ Model 1} & \multicolumn{2}{|l|}{ Model 2} & \multicolumn{2}{|c|}{ Model 3} \\
\hline & Coef. & $95 \% \mathrm{CI}$ & Coef. & $95 \% \mathrm{CI}$ & Coef. & $95 \% \mathrm{CI}$ \\
\hline \multicolumn{7}{|l|}{ Racial/ethnic group } \\
\hline \multicolumn{7}{|l|}{ Non-Latinx-Whites (ref. group) } \\
\hline Latinx & $-2.00 * * *$ & $-2.61,-1.39$ & $-0.89 *$ & $-1.63,-0.15$ & 0.71 & $-0.08,1.50$ \\
\hline Chinese & $-3.85 * * *$ & $-5.85,-1.84$ & $-2.65 *$ & $-4.79,-0.51$ & $-2.67 *$ & $-4.83,-0.51$ \\
\hline Asian Indian & -0.89 & $-3.02,1.25$ & -0.25 & $-2.53,2.03$ & -0.18 & $-2.41,2.05$ \\
\hline Filipino & 0.09 & $-1.70,1.88$ & 0.63 & $-1.32,2.58$ & 0.87 & $-1.05,2.79$ \\
\hline Japanese & -1.77 & $-4.53,0.99$ & -1.30 & $-3.94,1.35$ & -0.99 & $-3.71,1.74$ \\
\hline Korean & -2.38 & $-5.01,0.25$ & -1.08 & $-3.77,1.62$ & -1.02 & $-3.79,1.76$ \\
\hline Vietnamese & $-4.34 * *$ & $-7.07,-1.61$ & $-2.92 *$ & $-5.75,-0.0$ & -2.20 & $-5.08,0.69$ \\
\hline \multicolumn{7}{|l|}{ English proficiency (how well } \\
\hline \multicolumn{7}{|l|}{ English is spoken) } \\
\hline \multicolumn{7}{|l|}{ Very well (ref. group) } \\
\hline Well & & & $-2.62 * * *$ & $-4.04,-1.19$ & $-1.91 *$ & $-3.36,-0.46$ \\
\hline Not well & & & $-2.27 * * *$ & $-3.58,-0.96$ & -0.45 & $-1.78,0.87$ \\
\hline Not at all & & & $-2.12 *$ & $-3.82,-0.43$ & -0.05 & $-1.77,1.66$ \\
\hline \multirow{2}{*}{\multicolumn{7}{|c|}{$\begin{array}{l}\text { Nativity and time in the USA } \\
\text { Native-born (ref group) }\end{array}$}} \\
\hline & & & & & & \\
\hline Immigrated $<5$ years ago & & & 1.10 & $-1.64,3.84$ & 1.25 & $-1.53,4.03$ \\
\hline Immigrated 5-9 years ago & & & -0.08 & $-1.68,1.53$ & 0.19 & $-1.39,1.77$ \\
\hline Immigrated $10-14$ years ago & & & -0.04 & $-1.78,1.70$ & 0.31 & $-1.41,2.04$ \\
\hline Immigrated $15+$ years ago & & & -0.63 & $-1.64,0.38$ & $-1.21 *$ & $-2.22,-0.20$ \\
\hline Wald $F$-test, $H_{0}$ : Coefficients do & \multicolumn{2}{|c|}{$F(5,342)=3.01$} & \multicolumn{2}{|c|}{$F(5,342)=2.29$} & \multicolumn{2}{|c|}{$F(5,342)=2.26$} \\
\hline not differ across Asian subgroups & \multicolumn{2}{|c|}{ Prob $>F=0.011$} & \multicolumn{2}{|c|}{ Prob $>F=0.046$} & \multicolumn{2}{|c|}{ Prob $>F=0.048$} \\
\hline
\end{tabular}

Coefficient different from zero at $* p<0.05, * * p<0.01$, and $* * * p<0.001$. Model 3 controls for age, gender, insurance, income, education, health, and geographic variables. A complete set of coefficient estimates is available in the technical appendix, Table A1

Source: Medical Expenditure Panel Survey, 2014-2017 
Chinese is significantly smaller than that of Indians and Filipinos and that the mean for the Filipino subgroup is significantly higher than that of the Vietnamese subgroup.

\section{DISCUSSION}

Our study examined racial/ethnic differences in perceptions of provider communication with a special focus on Asian subgroups. Overall, Asians had less positive perceptions of provider communication than either Whites or Latinxs. These differences, however, were driven by Chinese-White and, possibly, Vietnamese-White differences. Notably, while Chinese, the largest Asian subgroup, had the least positive views of provider communication, Asian Indians and Filipinos, the next two largest Asian subgroups, typically had the most positive views among Asians. In fact, the mean of the provider communication scale for Filipinos was slightly higher than that of Whites. This makes the common practice of grouping all Asians into a single category especially problematic; if the two largest Asian subgroups occupy opposite ends of the distribution of provider communication, measures reported for all Asians are imprecise at best and at worst may obscure important disparities.

Our findings also suggest that differences in English proficiency and immigration status across ethnic groups account for some, but not nearly all, of the observed ethnic differences in perceptions of provider communication. Unlike Latinx-White differences in provider communication, Chinese-White differences persist even when all observed individual characteristics are held constant. More research is needed to explain why perceptions of provider communication are, on average, less positive for Chinese patients than for most other groups.

One possible explanation is that Chinese respondents might have preferences and expectations for health care that make interacting with health care providers less satisfying for them than for other groups. Traditional Chinese medicine (TCM) is a healing tradition that is accepted as mainstream in China and elsewhere in East Asia, even by medical doctors and is routinely practiced alongside western medicine. ${ }^{28}$ Some research suggests that Chinese and Vietnamese patients consider their providers' knowledge and acceptance of TCM to be a critical component of care quality. ${ }^{13}$ To the extent that medical doctors untrained in integrative medicine in the USA view TCM with skepticism or are ignorant of it, ${ }^{29}$ this may make patientprovider interactions less positive for Chinese patients than for other racial/ethnic groups.

\section{Limitations}

A limitation of this study is that, despite pooling several years of data, we lack the statistical power to detect differences in the mean provider communication scale relative to the three smallest Asian subgroups (Japanese, Korean, and Vietnamese) unless those differences are quite large. In particular, this may explain why Chinese respondents were significantly different from Whites while Vietnamese respondents were not.
Another limitation of our study is that, unlike most CAHPS studies, we do not have information about health plan characteristics. We therefore could not investigate whether there were systematic racial/ethnic differences in the quality of the health plans to which respondents belong and, if so, the extent to which such differences explain racial/ethnic differences in perceived provider communication. One study found that racial/ethnic differences in experiences with care are due more to within-plan differences than between-plan differences. ${ }^{17}$ Nevertheless, the absence of plan characteristics from our analysis is a limitation and should be considered when interpreting our results. Also, absence from our analysis are measures of cultural preferences related to medical care, patientprovider concordance with respect to race/ethnicity and language, and the availability of translation services, all of which may help explain the persistent difference observed between Whites and Chinese.

Finally, we cannot rule out the possibility that the observed racial/ethnic differences in the provider communication scale are due to differences in response styles. Some studies have found that Asians are less likely to use the highest response categories when answering survey questions compared to other groups, which may make their perceptions appear less positive. ${ }^{30}$ Research is needed to determine if "extreme response tendency" is particularly pronounced for Chinese patients, as this might explain the differences we observe in provider communication.

\section{CONCLUSIONS}

Prior work establishes that experiences with care among Asians are generally less positive than those among most other racial/ethnic groups. This study suggests, however, that past generalization about Asians' perceptions of provider communication, one aspect of the patient care experience, may have obscured important subgroup differences. Only Chinese patients (and possibly Vietnamese patients) rate their providers' communication less positively than do Whites. Asian Indian and Filipino patients hold views about their providers' communication that are at least as positive as those of Whites. While Japanese and Korean patients, on average, rate provider communication less positively than do Whites, differences are not statistically significant and the small sample for these groups makes these negative results inconclusive. Research is needed to determine if this pattern holds for other aspects of patients' experiences with care.

An implication of our findings is that researchers, policymakers, health plan executives, and others who produce and use data on patients' experiences with care should disaggregate results for Asians into ethnic subgroups whenever possible. Doing so for the three largest Asian subgroups, Chinese, Indians, and Filipinos, is particularly important because their perceptions of provider communication differ markedly. Recent trends in data collection may make this easier. Several 
CAHPS surveys, for example, now offer Chinese and Vietnamese questionnaires, and the Medicare Advantage and Prescription Drug Plan Disenrollment Reasons Survey asks about language spoken at home, with Chinese and Vietnamese included as explicit choices. ${ }^{31}$ Still, most data sources on patient experiences with care do not have detailed information on Asian background and cannot support estimates for even the largest Asian subgroups. Interventions aimed at narrowing Asian-White disparities in perceived provider communication will require an understanding of the medical needs, preferences, and expectations of Chinese and Vietnamese patients. This understanding will not happen without data on the care experiences of Asian subgroups in the USA.

Corresponding Author: James B. Kirby, PhD; Agency for Healthcare Research and Quality, Center for Financing, Access and Cost Trends, Rockville, MD, USA (e-mail: james.kirby@ahrq.hhs.gov).

\section{Compliance with Ethical Standards:}

Conflict of Interest: The authors declare that they do not have a conflict of interest.

\section{REFERENCES}

1. Moy E, Greenberg LG, Borsky AE. Community variation: disparities in health care quality between Asian and white medicare beneficiaries. Health Aff (Millwood). 2008;27(2):538-549.

2. Kang S-Y, Kim I, Kim W. Differential patterns of healthcare service use among Chinese and Korean immigrant elders. J Immigr Minor Health. 2016;18(6): 1455-1461.

3. Lee HY, Rhee TG, Kim NK, Ahluwalia JS. Health literacy as a social determinant of health in Asian American immigrants: findings from a population-based survey in California. J Gen Intern Med. 2015;30(8): 1118-1124.

4. Blendon RJ, Buhr T, Cassidy EF, et al. Disparities in physician care: experiences and perceptions of a multi-ethnic America. Health Aff (Millwood). 2008;27(2):507-517.

5. Morales LS, Elliott MN, Weech-Maldonado R, Spritzer KL, Hays RD. Differences in CAHPS adult survey reports and ratings by race and ethnicity: an analysis of the National CAHPS benchmarking data 1.0. Health Serv Res. 2001;36(3):595.

6. Smedley BD, Stith AY, Nelson AR. Committee on Understanding and Eliminating Racial and Ethnic Disparities in Health Care. Unequal treatment: confronting racial and ethnic disparities in health care. Paper presented at: National Academy of Science; 2003.

7. López G, Ruiz NG, Patten E. Key facts about Asian Americans, a diverse and growing population. Pew Research Center Accessed February. 2017;9:2018

8. Haviland AM, Elliott MN, Weech-Maldonado $\mathbf{R}$, Hambarsoomian $\mathbf{K}$, Orr N, Hays RD. Racial/ethnic disparities in Medicare Part D experiences. Med Care. 2012;50(Suppl):S40.

9. Haviland MG, Morales LS, Reise SP, Hays RD, Safety. Do health care ratings differ by race or ethnicity? The Joint Commission Journal of Quality. 2003;29(3): 134-145.

10. Johnson RL, Saha S, Arbelaez JJ, Beach MC, Cooper LA. Racial and ethnic differences in patient perceptions of bias and cultural competence in health care. J Gen Intern Med. 2004;19(2):101-110.

11. Murray-García JL, Selby JV, Schmittdiel J, Grumbach K, Quesenberry Jr CP. Racial and ethnic differences in a patient survey: patients values, ratings, and reports regarding physician primary care performance in a large health maintenance organization. Med Care. 2000:300310.
12. Ngo-Metzger Q, Legedza AT, Phillips RS. Asian Americans' reports of their health care experiences. J Gen Intern Med. 2004;19(2):111-119.

13. Ngo-Metzger $\mathbf{3}$, Massagli MP, Clarridge BR, et al. Linguistic and cultural barriers to care. J Gen Intern Med. 2003;18(1):44-52.

14. Palmer NR, Kent EE, Forsythe LP, et al. Racial and ethnic disparities in patient-provider communication, quality-of-care ratings, and patient activation among long-term cancer survivors. J Clin Oncol. 2014;32(36):4087.

15. Snyder RE, Cunningham W, Nakazono TT, Hays RD. Access to medical care reported by Asians and Pacific Islanders in a West Coast physician group association. Med Care Res Rev. 2000;57(2):196-215.

16. Martino SC, Elliott MN, Hambarsoomian $\mathbf{K}$, et al. Racial/ethnic disparities in Medicare beneficiaries' care coordination experiences. Med Care. 2016;54(8):765-771.

17. Weech-Maldonado R, Elliott MN, Morales LS, Spritzer K, Marshall GN Hays RD. Health plan effects on patient assessments of Medicaid managed care among racial/ethnic minorities. J Gen Intern Med. 2004;19(2): 136-145.

18. Weech-Maldonado R, Morales LS, Elliott M, Spritzer K, Marshall G, Hays RD. Race/ethnicity, language, and patients' assessments of care in Medicaid managed care. Health Serv Res. 2003;38(3):789-808.

19. Weech-Maldonado $\mathbf{R}$, Morales LS, Spritzer K, Elliott M, Hays RD. Racial and ethnic differences in parents' assessments of pediatric care in Medicaid managed care. Health Serv Res. 2001;36(3):575.

20. Burt J, Lloyd C, Campbell J, Roland M, Abel G. Variations in GPpatient communication by ethnicity, age, and gender: evidence from a national primary care patient survey. Br J Gen Pract. 2016;66(642):e47e52.

21. Lyratzopoulos G, Elliott M, Barbiere J, et al. Understanding ethnic and other socio-demographic differences in patient experience of primary care: evidence from the English General Practice Patient Survey. BMJ Qual Saf. 2012;21(1):21-29.

22. Brodie $\mathbf{K}, \mathbf{A b e l} \mathbf{G}$, Burt $\mathbf{J}$. Language spoken at home and the association between ethnicity and doctor-patient communication in primary care: analysis of survey data for South Asian and White British patients. BMJ Open. 2016;6(3).

23. National Health Service E. GP Patient Survey, Technical Annex, 2018 Annual Report. National Health Service; 2018.

24. Team MC. Summary of comparison of linear mean scoring with top-box scoring for MA CAHPS measures. 2017; https://ma-pdpcahps.org/ globalassets/ma-pdp/technical-specifications/comparison_of_linear_ mean_and_top_box_scoring_for_mcahps_final.pdf. Accessed 20 May 2020

25. Elliott MN, Cohea CW, Lehrman WG, et al. Accelerating improvement and narrowing gaps: trends in patients' experiences with hospital care reflected in HCAHPS public reporting. Health Serv Res. 2015;50(6):18501867.

26. Orr N, Elliott MN, Burkhart Q, Haviland A, Weinick RM. Racial/ethnic differences in Medicare experiences and immunization: the role of disease burden. Med Care. 2013:823-831.

27. StataCorp. Statistical Software, Release 16. In: College Station, Texas: StataCorp, LLC; 2019.

28. Harmsworth $\mathbf{K}$, Lewith $\mathbf{G}$. Attitudes to traditional Chinese medicine amongst Western trained doctors in the People's Republic of China. Soc Sci Med. 2001;52(1):149-153.

29. Hsiao AF, Hays RD, Ryan GW, et al. A Self-Report Measure of Clinicians' Orientation toward Integrative Medicine. Health Serv Res. 2005;40(5): 1553-1569

30. Mayer LA, Elliott MN, Haas A, Hays RD, Weinick RM. Less use of extreme response options by Asians to standardized care scenarios may explain some racial/ethnic differences in CAHPS scores. Med Care. 2016;54(1):38-44

31. Center for Medicare and Medicaid Services. Fee-for-Service CAHPS; 2020. https://www.cms.gov/Research-Statistics-Data-and-Systems/Research/CAHPS/FFSCAHPS. Accessed 6/11/2020.

Publisher's Note: Springer Nature remains neutral with regard to jurisdictional claims in published maps and institutional affiliations. 